\title{
Uterine Serous Carcinoma; Molecular Pathways and Role of Micrornas in Early Detection and Target Therapy
}

\author{
Ali Dastranj Tabrizi ${ }^{1}$, Shiva Rezaei ${ }^{2 *}$ and Leila Kafshdooz ${ }^{1}$ \\ ${ }^{1}$ Women's Reproductive Health Research Center, Tabriz University of Medical Sciences, Iran \\ ${ }^{2}$ Department of Animal Biology, University of Tabriz, Iran
}

Submission: September 15, 2017 ; Published: October 20, 2017

*Corresponding author: Shiva Rezaei, Department of Animal Biology, Faculty of Natural Sciences, University of Tabriz, Tabriz, Iran,

Email: Shiva-Rezaei@Tabrizu.ac.ir

\begin{abstract}
Uterine serous carcinoma (USC) in association with endometrial clear cell carcinoma (CCC) and grade 3 endometrioid carcinoma is responsible for $70-75 \%$ of endometrial carcinoma deaths and per se accounts for $39 \%$ of this cancer related mortality. Its tendency for early spread, leads to upstaging of 50-70\% of clinically stage I cancers at the time of operation. Involved molecular pathway(s) in this cancer differ from those of conventional endometriod carcinoma. It has been accepted that P53 mutation occurs as an early event in the endometrial serous carcinogenesis. Findings of P53 signature in the endometrial polyps and minor epithelial atypia (Endometrial Glandular DysplasiaEmGD) supported this assumption that mutation in PT53 may develop before apparent morphologic atypia (p53 signature), or occur in pre-existing malignant lesions of endometrium such as high grade endometriod carcinoma. Early detection through minimally-invasive approaches appears to be the gold strategy decreasing the uterine serous carcinoma related mortality. During last decades researchers have been interested in discriminating the specific and sensitive biomarkers such as microRNAs for early detection of invasive cancers. These recently explained microRNAs can be useful in monitoring the tumor response against different therapeutic agents as well as in tracing of disease process. In this review firstly we will concentrate on clinical aspects of uterine serous carcinoma and the essential molecular pathways of serous carcinogenesis.Then the main microRNAs involved in development of this cancer comprehensively will be discussed.
\end{abstract}

Keywords: Uterine serous carcinoma; Molecular pathways; MicroRNAs

Abbreviations: USC: Uterine Serous Carcinoma; EIC: Endometrial Intraepithelial Carcinoma; CCC: Clear Cell Carcinoma; mTOR: Mammalian Target of the Rapamycin; EMT: Epithelial Mesenchymal Transition

\section{Introduction}

As a high grade tumor, uterine serous carcinoma (USC) accounts for less than $10 \%$ of endometrial carcinomas (EC), but in association with endometrial clear cell carcinoma (CCC) and grade 3 endometrioid carcinoma is responsible for $70-75 \%$ of EC deaths [1] and per se accounts for $39 \%$ of this cancer related deaths [2]. As a prototype of type II endometrial carcinoma, USC is an aggressive disease and near $60-70 \%$ of the patients present with extrauterine spread at the time of diagnosis [2]. In contrast with more common type I endometrial carcinoma, serous carcinoma tends to occur in older age group and usually diagnosed at advanced stages [3]. Even among women who have not myometrial invasion, $33-50 \%$ of them will show extrauterine spread in comprehensive staging [4]. Its tendency for early spread, leads to upstaging of $50-70 \%$ of clinically stage I cancers at the time of operation [5]. Presentation of $46 \%$ of patients with USC and endometrial clear cell carcinoma in stage II-IV compared to $21 \%$ for all endometrial cancers confirms the common perception that these histotypes carry a worse prognosis due to advanced disease at the time of diagnosis [6]. Although the term "Endometrial Intraepithelial Carcinoma"(EIC) is widely used to designate the precursor lesion of uterine serous carcinoma, it should be acknowledged that "early serous carcinoma" or other alternative diagnostic terms have been suggested for use in clinical practice, in recognition that some serous carcinomas without invasion in the uterus are associated with extra-uterine spread $[7,8]$. For this reason Clement and Young considered EIC (Figure1) as a tiny focus of serous carcinoma and did not qualify it further other than to note its size and location and stressed 
that pathologists should indicate its malignant potential, in the pathology report when it is unaccompanied by typical serous carcinoma [9].

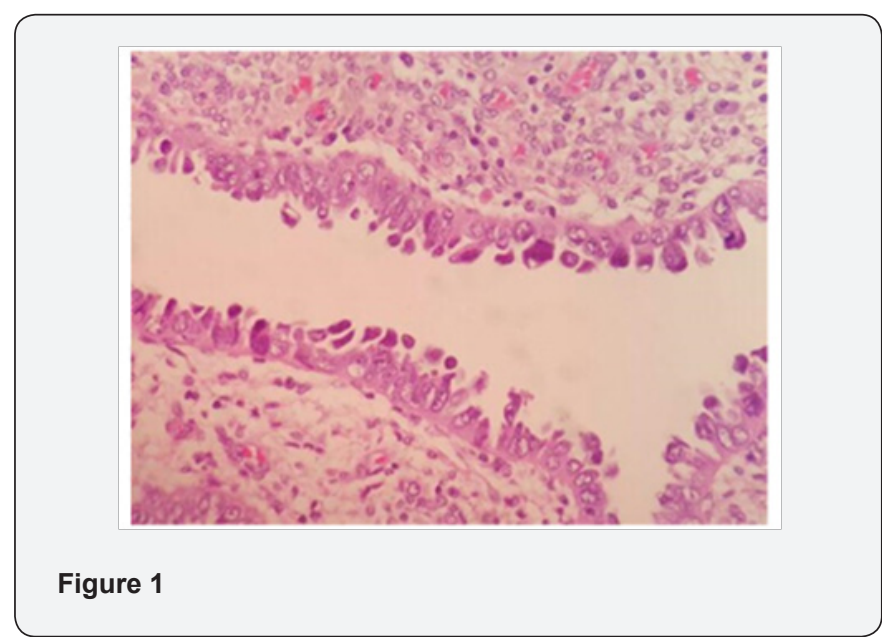

From histologic standpoint, USC presents as a high grade malignant tumor and shows slit like glands, short and thick papillary structures or solid aggregation of malignant epithelial cells (Figure 2). In high magnification the neoplastic cells have notable pleomorphic nuclei, prominent nucleoli and numerous mitosis including atypical types (Figure 3). It has been widely accepted that USC evolves via molecular genetic pathway(s) that differ from those of conventional endometriod carcinoma [10-15]. Although the dualistic module proposed by Bochman [16] has been conceptually useful and provided a framework for other important works, it is unable to explain these diversities in term of histology and molecular change in each of subgroups. Numerous studies proposed that P53 mutation occur as an early event in the endometrial serous carcinogenesis [17-20] (Figure 4) and based on a recent study on latent precursor (P53 signature) in the endometrial polyps [21], it has been suggested that the mutation in PT53 may develop before apparent morphologic atypia (p53 signature), associate with minor epithelial atypia (EmGD) or occur in pre-existing malignant lesions of endometrium ( high grade endometriod carcinoma) resulting in biphasic tumor pattern.

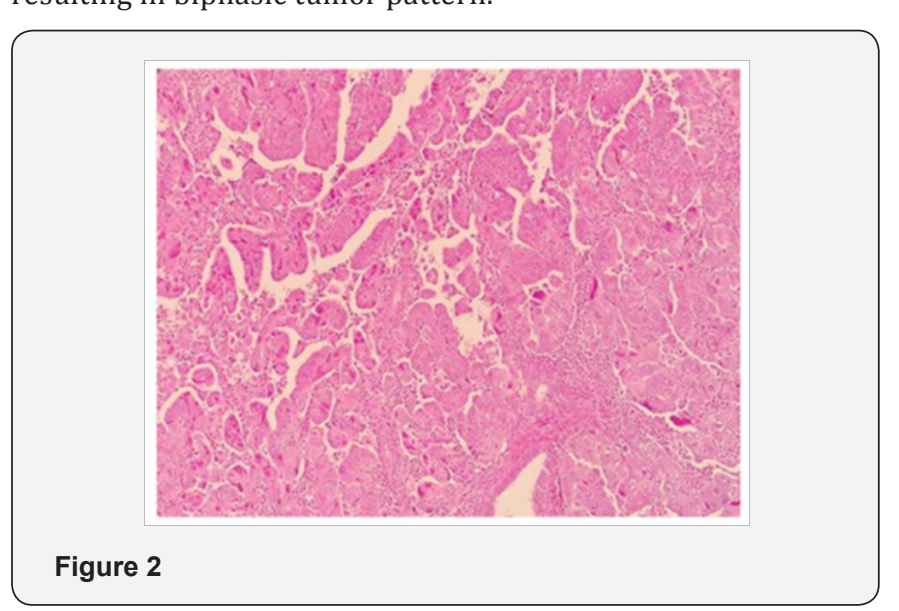

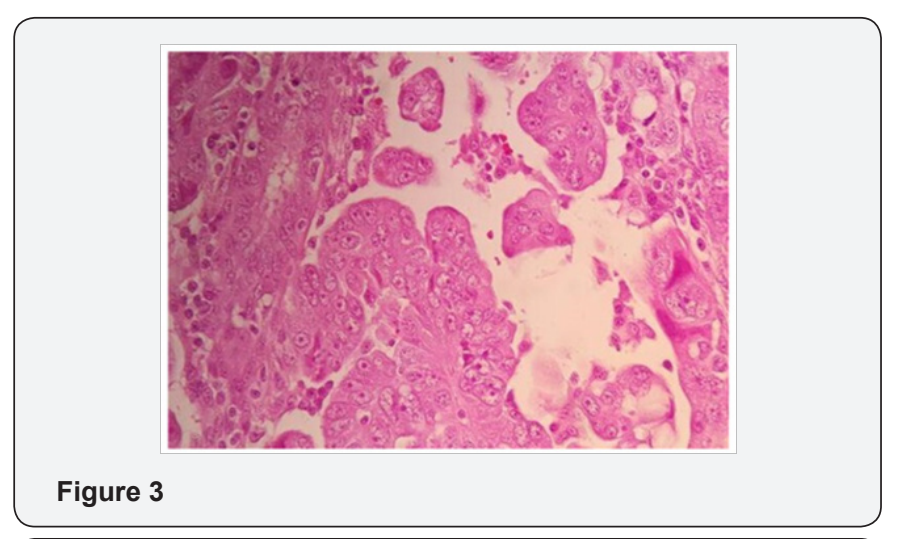

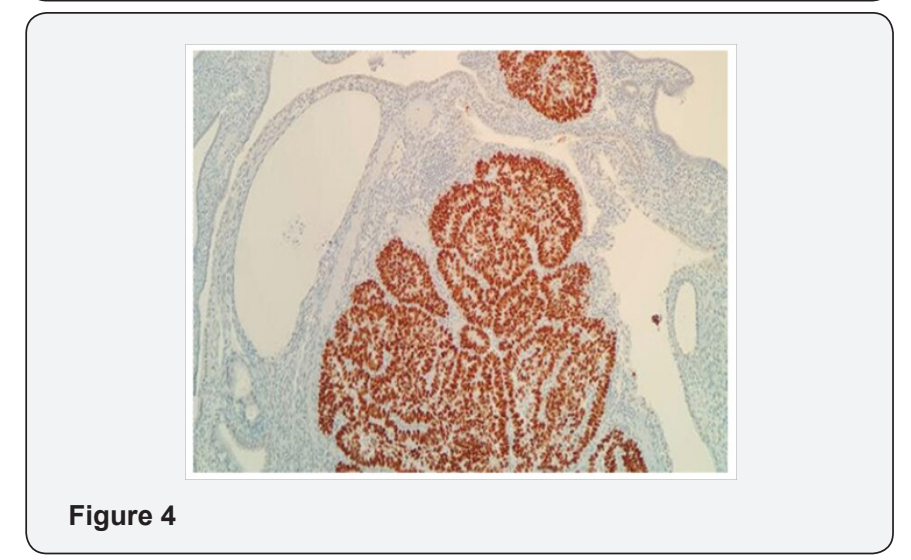

Early detection through minimally-invasive approaches appears to be the gold strategy decreasing the USC related mortality .During last decades researchers have been interested in discriminating the specific and sensitive biomarkers such as microRNAs detectable by simple methods. These recently explained microRNA can be useful in monitoring the tumor response against different treatments as well as in tracing of disease process [22]. However, the early stage diagnosis of cancers by microRNAs is still in its infancy.

MicroRNAs are small non-coding RNAs play special roles in post-transcriptional regulation of genes and are a large class of noncoding RNAs evolutionarily conserved in mammals [23]. Detection of miRNAs can be directed through various approaches including qRT-PCR, microarray and sequencing $[24,25]$. Accumulating studies have been conducted to define a valuable pattern of micoRNAs to improve early diagnostic and prognostic approaches. Accordingly, researchers from all over the world investigated microRNAs profiling in endometrial serous carcinoma patients. Current review has focused on the main genetic pathways involved in uterine serous carcinogenesis and latest literatures on microRNAs biomarker discovery validated for USC.

\section{1-Molecular Carcinogenesis in Uterine Serous Carcinoma}

Endometrial Serous Carcinomas commonly show mutation in p53, over-expression of cyclin E and HER2/neu, p16 dys- 
regulation, genetic alternations in E-cadherin and aberrations within the PI3K pathway [26]. A genome-wide analysis directed by Kuhn and coworkers showed that disruptions in p53, PI3K, and cyclin E pathways, were significantly detected in uterine serous carcinomas [27].

\section{P53}

Mutation in p53 is the most characteristic genetic alteration of non endometriod endometrial carcinomas [28]. As a tumor suppressor gene, p53 is located in 17p13.1, encodes the nuclear phosphoprotein p53 [29], and has important roles in preventing of inappropriate cell proliferation and maintaining the genome integrity following genotoxic stresses [30]. Loss of p53 function leads to apoptosis inhibition [31] and mutations in p53 can trigger signaling for transforming growth factor $\mathrm{b}$ (TGF-b) receptor, epidermal growth factor receptor, and mesenchymal epithelial transition (MET) $[32,33]$.

The level and activity of p53 is regulated by a complex network of several proteins such as HPV16 E6, WT-1, E1B/E4, SV40 T-antigen, MDM2, JNK, Pirh2, and PARP-1 [34]. Findings suggest that there are significant associations between advanced stages and high grade tumors with p53 mutations resulting in frequently poor outcome [35]. One hypothesis suggests that mutation in one allele occurs early during the development of serous carcinoma's precursor, meanwhile, normal second allele deficiency directs the progression toward serous carcinoma [36]. Another hypothesis discusses that serous carcinoma may be evolved through p53 mutation in previous endometrioid carcinoma based on presence of mixed endometrioid and serous carcinomas [37].

\section{P16 (CDKN2A)}

P16 located on chromosome 9 (9p21) [38], acts as a tumorsuppressor and negative regulator of the cell cycle [39] which is suggested as an critical marker to discrimination of uterine adenocarcinoma subtypes [40]. P16 inactivation was detected in approximately $45 \%$ of serous carcinomas. However, it is still not entirely clear what mechanism is involved in inactivation of P16 [41].

\section{PI3K pathway}

The phosphatidylinositol-3-kinase -AKT - mammalian target of the rapamycin (mTOR) pathway, an important mediator of different cell functions including the regulation of apoptosis, cell growth and proliferation, more frequently are disrupted in human malignancies [42]. The more common mutations in PI3K pathway are associated with PTEN, PIK3CA, and PIK3R1 [43-45].

\section{Wilms tumor 1 gene (WT1)}

The WT1 is a tumor suppressor gene located on the short arm of chromosome 11 at p13 [46]. There is a significant direct correlation between WT1 expression and histological grade as well as a trend toward worse clinical prognosis [47].

\section{E-cadherin}

E-cadherin as a key member of adhesion factors has an important role in cell polarity and integrity preservation and encoded by CDH1 gene $[41,48]$. It has extracellular Ca2+ binding sites to maintain intercellular stability by cell adhesion. In order to keep normal structure of the cells, the intracellular section of E-cadherin interplays with $\beta$-catenin and forms connections [49]. Reduced E-cadherin expression is associated with advanced stages in endometrial cancers [48]. Evidence showed that downregulation of E-cadherin may be as a result of hypermethylation of promoter or Loss of heterozygosity [50].

\section{HER2/neu}

A multiple lines of evidences demonstrate that gene amplification of epidermal growth factor receptor II or HER2/ neu and its protein over- expression are associated with several human cancers including endometrial malignancies and poor prognosis [51]. This gene is defined as an essential oncogene has functions in signal transduction. HER2 up-regulation or amplification is more common among USC in comparison with endometrioid carcinoma [52-54] that comes along unfavorable prognostic factors.

\section{Cyclin E}

Cyclin E encoded by CCNE has key function in the regulation of G1 phase to S phase transition during cell cycle. Up-regulation of cyclin E leads to speed up in cell cycle through G1 phase by interplaying with cyclin-dependent kinase-2 (CDK-2). Findings suggested an important association between overexpression of cyclin E and endometrial carcinomas, although details of involved mechanisms remain to be elucidated. Cassia and coworkers for the first time reported that overexpression of cyclin E could be as a result of gene amplification which is more commonly detected in non-endometrioid endometrial carcinomas [55].

\section{MicroRNAs Regulatory Function}

MicroRNAs regulate the expression of mRNA either by its degradation or translation silencing, depending on the recognition of a target sequence within $3^{\prime}$ UTR of mRNAs. MicroRNAs recognize a 6-7 nucleotide region in their target mRNAs complementary to the "seed" sequence of the microRNA. This seed site is determined between nucleotide positions 2 to 8 from the $5^{\prime}$ region of the microRNA. In case of accurate basepairing with the $3^{\prime}$ UTR region of the mRNA target, microRNAs direct a cleavage in the target strand. Although, inaccurate complementary causes the inhibition of mRNA translation either at initiation or during elongation phases [22,56,57]. It should be pointed that a unique microRNA may have multiple mRNA targets. Also, a set of microRNAs may be included in the regulation of a single mRNA [58-60].

\section{Function of microRNAs in cancer}

Capability of microRNA to use as novel biomarkers: Detection of microRNA- based biomarkers will affect the 
diagnostic approach in personalized medicine dramatically. Lin4 was the first microRNA distinguished in C. elegans acting as down- regulator of LIN-14 [23]. Additionally, there are a number of reports suggesting the presence of microRNAs in body fluids e.g. blood, released by tumor cells [61-63].

For the first time, Lawrie and colleagues recognized the first blood- based microRNA associated with tumor in sera of B-cell lymphoma subjects [64]. Afterward, several groups have endeavored to detect specific and sensitive tumor secreted biomarkers related with different malignancy. On the other hand, microRNAs may be proper therapeutic agents holding promise as candidates for microRNA inhibition and replacement therapies in targeted treatments [65]. Also, they preserve essential features, such as special stability in body fluids, simple and pervasive determination approaches and more importantly the ability to screening and regular monitoring of the diseases and its response to therapies, encouraging the researchers in microRNA baesd- biomarker discoveries [66].

Further deep analysis suggest that tumor cells direct the signaling mediators like microRNAs in cell to cell communications and persuade transformation in the neighboring or distant regions. Accordingly, the cells more likely secrete distinct microRNAs and the other cells recognize and taken up them by molecular mechanisms remain to be fully discovered $[67,68]$. In this regard, the cells take special measures to keep microRNAs out of digestion by endogenous RNase including their association with RNA binding proteins like Argonaute2 [68].

Misregulation of microRNAs in cancers: The literatures reported both oncogenic and tumor suppressive functions for these group of noncoding RNAs. It was shown that microRNAs can disturb normal homeostasis of the cells and induce abnormality in various pivotal pathways ultimately lead to increased proliferation, promotion of angiogenesis, epithelialmesenchymal transition, inhibition of apoptosis, invasion, metastasis, resistance against therapies and so on [69-71]. Moreover, argonaute2 [72-74] DROSHA and DICER [59-75] as critical components of the microRNA regulatory pathway, might be deregulated in some malignancies.

MicroRNA biomarkers detected in endometrial serous carcinoma during recent years: A number of Investigations have evaluated the possible relation between endometrial serous carcinoma and certain microRNAs. A study by Hiroki and colleagues suggested 54 down-regulated (such as miR101, miR-10b*, miR-29b and miR-152) and 66 upregulated microRNAs (including miR-205, miR-200a and miR-200b), could be considered as markers to discriminating endometrial serous carcinoma patients from normal cases. They also considered any significant relationship between differential expressions of miRNAs with clinicopathological characteristics of the patients. Their results demonstrated that down- regulation of miR$10 b^{*}$, miR-29b, and miR-455-5p detected in patients with more invasive stages, had key roles in cancer metastatic progression [76].

At the same time, another group reported that miR-22 is specifically upregulated in endometrial serous carcinomas compared to uterine carcinosarcomas but the expression of miR-182 is reduced [77]. In another study, Hiroki and coworkers showed that the expression of miR-34b decreased in comparison with normal subjects. Their findings suggested that $\mathrm{CpG}$ island hypermethylation is associated with down-regulation of miR$34 \mathrm{~b}$ expression [78].

In a more comprehensive study Devor, et al. provided the microRNA pattern of endometrial endometrioid adenocarcinomas and serous adenocarcinomas. They significantly detected down- regulation of seven microRNAs and upregulation of 13 microRNAs in both groups. However, each type of endometrial cancer had also specific pattern of microRNA misregulation. For example, the expression of miR-155 and miR-370 significantly increased in serous adenocarcinomas in comparison with control cases ( $p=0.049$ and $p=0.024$, respectively) [79]. A recent study, defined that miR-106b was down-regulated in highly invasive endometrial serous carcinoma cells. It could conduct the suppression of TWIST1 expression, as an essential mediator of epithelial mesenchymal transition (EMT), resulting in more invasive phenotypes of endometrial cancers [80].

In another investigation, the expression of miR-182 and its target (Cullin-5, a cullin-RING E3 ubiquitin ligase have function in various types of malignancies) were assessed by Devor and coworkers. They reported significantly reduction of Cullin-5 expression in both case groups (endometrioid and serous endometrial adenocarcinomas) compared with normal samples. Although, they showed that serous cancer subjects had more decline (-4.3-fold) than endometrioid types ( -2.9 -fold). They asserted that overexpression of miR-182 led to the reduction of Cullin-5 expression [81].

A more recent case- control study, exposed miRNAs pattern in African- American cases having uterine serous carcinoma and compared them with matched controls. The patients were followed- up for a medium time of 43 months. They declared that 649 micoRNAs had differential expression between tumor and normal subjects and presented miR-223 as a death risk factor. Their results displayed overexpression of miR-223 associated with disease recurrence and poor prognosis [82].

\section{Conclusion}

MicroRNAs as mediators of pivotal regulatory pathways have certain notable features awarding possibility to use them as novel diagnostic and prognostic biomarkers, targeted anti-cancer therapies and overcoming drug resistance. Despite the wide variety of microRNAs assumed to be involved in endometrial serous carcinomas, in some cases the inverse findings are remarkable from one study to another, more likely as a result of 
the inconsistency in sample preparation procedures, adopting the determination and normalization methods and especially the differentiation caused by genetic pools and environmental factors of initial subjects. As yet, the lack of a worldwide standard method to determination of microRNAs has been led to delays in its transition from lab to clinic.

Common treatments in combination with microRNA replacement and prophylactic strategies have obtained substantial promise to cure more invasive cancers. However, future studies should answer which panel of microRNAs has actually differential expression between endometrial serous carcinoma in comparison with normal controls and other types of endometrial carcinoma. Altogether, more prospective and comprehensive studies using standard procedures are necessary to exactly elucidation of microRNA- based biomarkers for early detection and predicting the invasive phenotypes.

\section{References}

1. Hamilton CA, Cheung MK, Osann K, Chen L, Teng NN, et al. (2006) Uterine papillary serous and clear cell carcinomas predict for poorer survival compared to grade 3 endometrioid corpus cancers. Br J Cancer Mar 94(5): 642-646.

2. Gatius S, Matias-Guiu X (2016) Practical issues in the diagnosis of serous carcinoma of the endometrium. Mod Pathol suppl 1: S45-S58.

3. del Carmen MG, Birrer M, Schorge JO (2012) Uterine papillary serous cancer: a review of the literature. Gynecol Oncol 127: 651-661.

4. Gehrig PA, Groben PA, Fowler WC, Walton LA, Van Le L (2001) Noninvasive papillary serous carcinoma of the endometrium. Obstet Gynecol 97(1): 153-157.

5. Faratian D, Stillie A, Busby-Earle RM, Cowie VJ, Monaghan H (2006) A review of the pathology and management of uterine papillary serous carcinoma and correlation with outcome. Int J Gynecol Cancer 16(3): 972-978.

6. Creasman WT, Kohler MF, Odicino F, Maisonneuve P, Boyle P (2004) Prognosis of papillary serous, clear cell, and grade 3 stage I carcinoma of the endometrium. Gynecol Oncol 95: 593-596.

7. Fadare 0, Zheng W (2008) Endometrial glandular dysplasia (EmGD): morphologically and biologically distinctive putative precursor lesions of type II endometrial cancers. Diagn Pathol 3(6): 1-9.

8. Zheng W, Khurana R, Farahmand S, Wang Y, Zhang ZF (1998) P53 immunostaining as a significant adjunct diagnostic method for uterine surface carcinoma: precursor of uterine papillary serous carcinoma. Am J Surg Pathol 22: 1463-1473.

9. Clement PB, Young RH (2004) Non-endometrioid carcinomas of the uterine corpus: a review of their pathology with emphasis on recent advances and problematic aspects. Adv Anat Pathol 11(3): 117-142.

10. Sasano H, Comerford J, Wilkinson DS, Schwartz A, Garrett CT (1990) Serous papillary adenocarcinoma of the endometrium; Analysis of proto-oncogene amplification, flow cytometry, estrogen and progesterone receptors, and immunohistochemistry. Cancer 65(7): 1545-1551.

11. Prat J, Oliva E, Lerma E, Matias-Guiu X (1994) Uterine papillary serous adenocarcinoma. A 10 -case study of $\mathrm{p} 53$ and c-erbB-2 expression and DNA content. Cancer 74(6): 1778-1783.

12. Santin AD (2003) Her2/neu "overexpression" has the Achilles' heel of uterine serous papillary carcinoma been exposed? Gynecol Oncol 88(3): 263-265.
13. Bancher-Todesca D, Gitsch G, Williams KE, Kohlberger P, Neunteufel W, et al. (1998) p53 protein overexpression: A strong prognostic factor in uterine papillary serous carcinoma. Gynecol Oncol 71: 59-63.

14. Soslow RA, Shen PU, Chung MH, Isacson C (1998) Distinctive p53 and mdm2 immunohistochemical expression profiles suggest different pathogenetic pathways in poorly differentiated endometrial carcinoma. Int J Gynecol Pathol 17(12): 129-134.

15. Kounelis S, Kapranos N, Kouri E, Coppola D, Papadaki H, et al. (2000) Immunohistochemical profile of endometrial adenocarcinoma: A study of 61 cases and review of the literature. Mod Pathol 13(4): 379-388.

16. Bokhman JV (1983) Two pathogenetic types of endometrial carcinoma. Gynecol oncol 15(1): 10-17.

17. Sherman M, Bur ME, Kurman RJ (1995) p53 in endometrial cancers and its putative precursors: evidence for diverse pathways of tumorigenesis. Hum Pathol 26(11): 1268-1274.

18. Tashiro H, Isacson C, Levine R, Kurman RJ, Cho KR, et al. (1997) p53 gene mutations are common in uterine serous carcinoma and occur early in their pathogenesis. Am J Pathol 150(1): 177-185.

19. Sherman ME (2000) Theories of endometrial carcinogenesis: a multidisciplinary approach. Mod Pathol 13(3): 295-308.

20. Liang SX, Cheng L, Chambers SK, Zhou Y, Schwartz PE, et al. (2004) Endometrial glandular dysplasia, a newly defined precursor lesion of uterine papillary serous carcinoma: a molecular study. Intl J Surg Pathol 12(4): 319-331.

21. Jarboe EA, Pizer E, Miron A, Monte N, Mutter GL, (2009) Evidence for a Latent Precursor (p53 Signature) that May Precede Serous Endometrial Intraepithelial Carcinoma. Mod Pathol 22(3): 345-350.

22. Saikumar J, Ramachandran K, Vaidya VS (2014) Noninvasive Micromarkers Clin Chem 60(9): 1158-1173.

23. Lee RC, Feinbaum RL, Ambros V (1993) The C. elegans heterochronic gene lin- 4 encodes small RNAs with antisense complementarity to lin14. Cell 75: 843-854.

24. Kroh EM, Parkin RK, Mitchell PS, Tewari M (2010) Analysis of circulating microRNA biomarkers in plasma and serum using quantitative reverse transcription-PCR (qRT-PCR). Methods. 50(4): 298-301.

25. Pritchard CC, Cheng HH, Tewari M (2012) MicroRNA profiling: approaches and considerations. Nat Rev Genet 13(5): 358-369.

26. Micci F, Teixeira MR, Haugom L, Kristensen G, Abeler VM, et al. (2004) Genomic aberrations in carcinomas of the uterine corpus. Genes, Chromosomes and Cancer 40(3): 229-246.

27. Kuhn E, Wu RC, Guan B, Wu G, Zhang J, et al. (2012) Identification of Molecular Pathway Aberrations in Uterine Serous Carcinoma by Genome-wide Analyses. JNCI 104(19): 1503-1513.

28. Alkushi A, Köbel M, Kalloger SE, Gilks CB (2010) High-grade endometrial carcinoma: serous and grade 3 endometrioid carcinomas have different immunophenotypes and outcomes. Int J Gynecol Pathol 29(4): 343-350.

29. Ying TH, Tseng CJ, Tsai SJ, Hsieh SC, Lee HZ, et al. (2011) Association of p53 and CDKN1A genotypes with endometriosis. Anticancer res 31(12): 4301-4306.

30. Zhao J, Wu G, Bu F, Lu B, Liang A, et al. (2010) Epigenetic silence of ankyrin-repeat-containing, SH3-domain-containing, and prolinerich-region-containing protein 1 (ASPP1) and ASPP2 genes promotes tumor growth in hepatitis B virus-positive hepatocellular carcinoma. Hepatology 51(1): 142-153.

31. Reimers MS, Zeestraten EC, Kuppen PJ, Liefers GJ, van de Velde CJ (2013) Biomarkers in precision therapy in colorectal cancer. Gastroenterol Rep (Oxf) 1(3): 166-183. 
32. Grugan KD, Vega ME, Wong GS, Diehl JA, Bass AJ, et al. (2013) A common p53 mutation $(\mathrm{R} 175 \mathrm{H})$ activates c-Met receptor tyrosine kinase to enhance tumor cell invasion. Cancer Biol Ther 14(9): 853-859.

33. Martello G, Rosato A, Ferrari F, Manfrin A, Cordenonsi M, et al. (2010) A MicroRNA targeting dicer for metastasis control. Cell 141(7): 11951207.

34. Bai L, Zhu W-G (2006) p53: structure, function and therapeutic applications. J Cancer Mol 2(4): 141-153.

35. Inaba F, Kawamata H, Teramoto T, Fukasawa I, Inaba N, et al. (2005) PTEN and p53 abnormalities are indicative and predictive factors for endometrial carcinoma. Oncol Rep 13(1): 17-24.

36. Tashiro H, Isacson C, Levine R, Kurman RJ, Cho KR, et al. (1997) p53 gene mutations are common in uterine serous carcinoma and occur early in their pathogenesis. Am J Pathol 150(1): 177-185.

37. Matias-Guiu X, Catasus L, Bussaglia E, Lagarda H, Garcia A, et al. (2001) Molecular pathology of endometrial hyperplasia and carcinoma. Hum Pathol 32(6): 569-577.

38. Nobori T, Miura K, Wu DJ, Lois A, Takabayashi K (1994) Deletions of the cyclin-dependent kinase-4 inhibitor gene in multiple human cancers. Nature 368(6473): 753-756.

39. Serrano M, Hannon GJ, Beach D (1993) A new regulatory motif in cell-cycle control causing specific inhibition of cyclin D/CDK4. Nature 366(6456): 704-707.

40. Yemelyanova A, Ji H, Shih IM, Wang TL, Wu LS, et al. (2009) Utility of p16 expression for distinction of uterine serous carcinomas from endometrial endometrioid and endocervical adenocarcinomas: immunohistochemical analysis of 201 cases. Am J Surg Pathol 33(10): 1504-1514.

41. Samarnthai N, Hall K, I-Tien Y (2010) Molecular Profiling of Endometrial Malignancies. Obstet Gynecol Int 16.

42. Yip PY (2015) Phosphatidylinositol 3-kinase-AKT-mammalian target of rapamycin (PI3K-Akt-mTOR) signaling pathway in non-small cell lung cancer. Transl Lung Cancer Res 4(2): 165-176.

43. Hayes MP, Douglas W, Ellenson LH (2009) Molecular alterations of EGFR and PIK3CA in uterine serous carcinoma. Gynecol Oncol 113(3): 370-373.

44. Catasus L, Gallardo A, Cuatrecasas M, Prat J (2009) Concomitant PI3KAKT and p53 alterations in endometrial carcinomas are associated with poor prognosis. Mod Pathol 22(4): 522-529.

45. Urick ME, Rudd ML, Godwin AK, Sgroi D, Merino M, et al. (2011) PIK3R1 (p85\{alpha\}) is somatically mutated at high frequency in primary endometrial cancer. Cancer Res 71(12): 4061-4067.

46. Pritchard-Jones K, Hastie N (1989) Wilms' tumour as a paradigm for the relationship of cancer to development. Cancer surveys 9(3): 555578

47. Dupont J, Wang X, Marshall DS, Leitao M, Hedvat CV, et al. (2004) Wilms Tumor Gene (WT1) and p53 expression in endometrial carcinomas: a study of 130 cases using a tissue microarray. Gynecol Oncol 94(2): 449455

48. Xiong S, Klausen C, Cheng J-C, Leung PC. (2016) Activin B promotes endometrial cancer cell migration by down-regulating E-cadherin via SMAD-independent MEK-ERK1/2-SNAIL signaling. Oncotarget 7(26) 40060-40072.

49. Hu QP, Kuang JY, Yang QK, Bian XW, Yu SC (2016) Beyond a tumor suppressor: Soluble E- cadherin promotes the progression of cancer. Int J Cancer 138(12): 2804-2812.

50. Llobet D, Pallares J, Yeramian A, Santacana M, Eritja N, et a. (2009) Molecular pathology of endometrial carcinoma: practical aspects from the diagnostic and therapeutic viewpoints. J Clin Pathol 62(9): 777 785 .

51. Slomovitz BM, Broaddus RR, Burke TW, Sneige N, Soliman PT, et al. (2004) Her-2/neu overexpression and amplification in uterine papillary serous carcinoma. J Clin Oncol 22(15): 3126-3132.

52. Morrison C, Zanagnolo V, Ramirez N, Cohn DE, Kelbick N, et al. (2006) HER-2 is an independent prognostic factor in endometrial cancer: association with outcome in a large cohort of surgically staged patients. J Clin Oncol 24(15): 2376-2385.

53. Engelsen IB, Stefansson IM, Beroukhim R, Sellers WR, Meyerson M, et al. (2008) HER-2/neu expression is associated with high tumor cell proliferation and aggressive phenotype in a population based patient series of endometrial carcinomas. Int J Oncol 32(2): 307-316.

54. Konecny GE, Santos L, Winterhoff B, Hatmal M, Keeney GL, et al. (2009) HER2 gene amplification and EGFR expression in a large cohort of surgically staged patients with nonendometrioid (type II) endometrial cancer. Br J Cancer 100(1): 89-95.

55. Cassia R, Moreno-Bueno G, Rodríguez-Perales S, Hardisson D, Cigudosa JC, et al. (2003) Cyclin E gene (CCNE) amplification and hCDC4 mutations in endometrial carcinoma. J Pathol 201(4): 589-595.

56. Park JH, Shin C (2014) MicroRNA-directed cleavage of targets: Mechanism and experimental approaches. BMB REP 47(8): 417-423.

57. Wu L, Fan J, Belasco JG (2006) MicroRNAs direct rapid deadenylation of mRNA. Proc Natl Acad Sci USA 103(11): 4034-4039.

58. Bartel DP (2004) MicroRNAs: genomics, biogenesis, mechanism, and function. Cell 116(2): 281-297.

59. Krol J, Loedige I, Filipowicz W (2010) The widespread regulation of microRNA biogenesis, function and decay. Nat Rev Genet 11(9): 597 610.

60. O'Day E, Lal A (2010) MicroRNAs and their target gene networks in breast cancer. Breast Cancer Res 12(2): p. 201.

61. Creemers EE, Tijsen AJ, Pinto YM (2012) Circulating MicroRNAs Novel Biomarkers and Extracellular Communicators in Cardiovascular Disease? Circ Res 110(3): 483-495.

62. Chen X, Ba Y, Ma L, Cai X, Yin Y, et al. (2008) Characterization of microRNAs in serum: a novel class of biomarkers for diagnosis of cancer and other diseases. Cell Res 18(10): 997-1006.

63. Mitchell PS, Parkin RK, Kroh EM, Fritz BR, Wyman SK (2008) PogosovaAgadjanyan EL, et al. Circulating microRNAs as stable blood-based markers for cancer detection. Proc Natl Acad Sci USA 105(30): 1051310518.

64. Lawrie CH, Gal S, Dunlop HM, Pushkaran B, Liggins AP, et al. (2008) Detection of elevated levels of tumour-associated microRNAs in serum of patients with diffuse large B-cell lymphoma. Br J Haematol 141(5): 672-675.

65. Christopher AF, Kaur RP, Kaur G, Kaur A, Gupta V, et al. (2016) MicroRNA therapeutics: Discovering novel targets and developing specific therapy. Perspect Clin Res 7(2): 68-74.

66. Zhao YN, Chen GS, Hong SJ (2014) Circulating MicroRNAs in gynecological malignancies: from detection to prediction. Exp Hematol Oncol 3: 14

67. Wang K, Zhang S, Weber J, Baxter D, Galas DJ (2010) Export of microRNAs and microRNA-protective protein by mammalian cells. Nucleic Acids Res 38(20): 7248-7259.

68. Gibbings DJ, Ciaudo C, Erhardt M, Voinnet O (2009) Multivesicular bodies associate with components of miRNA effector complexes and modulate miRNA activity. Nat Cell Biol 11(9): 1143-1149. 
69. Ma L, Reinhardt F, Pan E, Soutschek J, Bhat B, et al. (2010) Therapeutic silencing of miR-10b inhibits metastasis in a mouse mammary tumor model. Nat Biotechnol 28(4): 341-347.

70. Li Y, Kowdley KV (2012) MicroRNAs in Common Human Diseases. Genomics Proteomics Bioinformatics 10(5): 246-253.

71. Chen W, Cai F, Zhang B, Barekati Z, Zhong XY (2013) The level of circulating miRNA- 10b and miRNA-373 in detecting lymph node metastasis of breast cancer: potential biomarkers. Tumour Biol 34(1): 455-462.

72. Carmell MA, Xuan Z, Zhang MQ, Hannon GJ (2002) The Argonaute family: tentacles that reach into RNAi, developmental control, stem cell maintenance, and tumorigenesis. Genes Dev 16(21): 2733-2742.

73. Nelson P, Kiriakidou M, Sharma A, Maniataki E, Mourelatos Z (2003) The microRNA world: small is mighty. Trends Biochem Sci 28(10): 534540 .

74. Esquela-Kerscher A, Slack FJ (2006) Oncomirs - microRNAs with a role in cancer. Nat Rev Cancer 6(4): 259-269.

75. Gurtner A, Falcone E, Garibaldi F, Piaggio G (2016) Dysregulation of microRNA biogenesis in cancer: (2016) the impact of mutant p53 on Drosha complex activity. J Exp Clin Cancer Res 35: 45.

76. Hiroki E, Akahira Ji, Suzuki F, Nagase S, Ito K, et al. (2010) Changes in microRNA expression levels correlate with clinicopathological features and prognoses in endometrial serous adenocarcinomas. Cancer Sci 101(1): 241-249.
77. Ratner ES, Tuck D, Richter C, Nallur S, Patel RM, et al. (2010) MicroRNA Signatures Differentiate Uterine Cancer Tumor Subtypes. Gynecol Oncol 118(3): 251-257.

78. Hiroki E, Suzuki F, Akahira Ji, Nagase S, Ito K, et al. (2012) MicroRNA$34 \mathrm{~b}$ functions as a potential tumor suppressor in endometrial serous adenocarcinoma. Int J Cancer 131(4): E395-E404.

79. Devor EJ, Hovey AM, Goodheart MJ, Ramachandran Sh, Leslie KK (2011) MicroRNA expression profiling of endometrial endometrioid adenocarcinomas and serous adenocarcinomas reveals profiles containing shared, unique and differentiating groups of microRNAs. Oncol Rep 26(4): 995-1002.

80. Dong P, Kaneuchi M, Watari H, Sudo S, Sakuragi N (2014) MicroRNA106b modulates epithelial-mesenchymal transition by targeting TWIST1 in invasive endometrial cancer cell lines. Mol Carcinog 53(5): 349-359.

81. Devor EJ, Schickling BM, Reyes HD, Warrier A, Lindsay B, et al. (2016) Cullin-5, a ubiquitin ligase scaffold protein, is significantly underexpressed in endometrial adenocarcinomas and is a target of miR-182. Oncol Rep 35(4): 2461-2465.

82. Lee LJ, Howitt BE, Fendler W, Stawiski K, Bu P, et al. (2017) miRNA profiling in a case: Control study of African American women with uterine serous carcinoma (USC). J Clin Oncol 35:15.

\begin{tabular}{|l|}
\hline \multicolumn{1}{|c|}{ Your next submission with Juniper Publishers } \\
will reach you the below assets \\
- Quality Editorial service \\
- Swift Peer Review \\
- Reprints availability \\
- E-prints Service \\
- Manuscript Podcast for convenient understanding \\
- Global attainment for your research \\
- Manuscript accessibility in different formats \\
( Pdf, E-pub, Full Text, Audio) \\
- Unceasing customer service \\
Track the below URL for one-step submission \\
https://juniperpublishers.com/online-submission.php \\
\hline
\end{tabular}

